
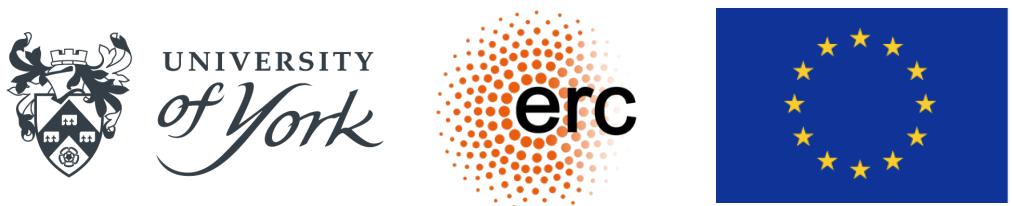

Teacher Selection Project Working Paper

Version 01.06.20

\title{
The development and testing of an online scenario- based learning activity to prepare preservice teachers for teaching placements
}

Robert M. Klassen ${ }^{1}$, Lisa Bardach ${ }^{1}$, Jade Rushby ${ }^{1}$, Liz Maxwell ${ }^{1}$, Tracy Durksen ${ }^{2}$, and Lynn Sheridan ${ }^{3}$

\author{
${ }^{1}$ University of York, UK \\ ${ }^{2}$ University of New South Wales, Australia \\ ${ }^{3}$ University of Wollongong, Australia
}

This Working Paper reports in-progress work that is not yet peer reviewed. The purpose of the Working Paper is to stimulate discussion and to contribute to the advancement of knowledge. Please check our project website for news of recent publications. This work is supported by the European Research Council (grant \#647234 SELECTION). The fifth author also acknowledges the support provided by the New South Wales Department of Education through a funded partnership with the University of New South Wales, Australia. 


\title{
The development and testing of an online scenario-based learning activity to prepare preservice teachers for teaching placements
}

\begin{abstract}
In this study we report the development and testing of a scenario-based learning (SBL) activity delivered to 191 preservice teachers in the UK and Australia before the start of a school-based teaching placement. SBL uses interactive, realistic classroom scenarios, coupled with self-reflection and feedback from experienced teachers to enhance the selfefficacy and classroom readiness of preservice teachers. Two studies are presented. Findings from Study 1 (40 preservice teachers from the UK) indicated that participants found the activity engaging and useful, and reported a high level of agreement that the activity increased self-efficacy and preparedness for teaching placements. Findings from Study 2 (151 preservice teachers from Australia) revealed that most participants reported higher levels of placement self-efficacy and preparedness. A quasi-experimental design in Study 2 revealed statistically significant increases in emotional classroom readiness, but not in teaching self-efficacy, motivational classroom readiness, or cognitive classroom readiness. We conclude that an SBL activity can play an important role in preparing preservice teachers for school-based teaching placements.
\end{abstract}

\section{Introduction}

The teaching placement ${ }^{1}$ is widely considered to be of fundamental importance in an initial teacher training (ITT) program (Ronfeldt, 2015) because it forms the closest approximation of professional practice. A preservice teacher's success in an ITT program rests on how well they navigate the challenges of this placement; failure or poor performance is not insurmountable, but it augurs poorly for continuation in the profession (NCATE, 2010). Entering the classroom for the first time presents cognitive, motivational, and emotional challenges (Caires, Almeida, \& Vieira, 2012) If preservice teachers are not well-prepared, these challenges can lead to a kind of 'practice shock' where idealism about the profession clashes with the reality that they encounter in schools (Wideen, Mayer-Smith, \& Moon, 1998).

Teacher preparation programs use multiple approaches-lectures, seminar groups, role-plays - to prepare preservice teachers to enter what can be widely variable and highly challenging classroom contexts. However, structured simulated classroom interventionssuch as scenario-based learning (SBL) approaches-have not been systematically examined in teacher education, even though they are shown to be effective for training outside education (e.g., Errington, 2011). In this article, we present two studies describing the development and administration of an online SBL activity designed to increase preservice teachers' readiness to embark on teaching placements during their teacher education program.

The importance of the teaching placement. For preservice teachers, the teaching placement is the first prolonged experience of professional practice, with research linking performance during the teaching placement with a teacher's later effectiveness (Goldhaber, Krieg, \& Theobald, 2017). For ITT in England, the requirement of previous school experience has recently been removed, meaning candidates may enter ITT programmes with no or little school experience (DfE, 2020). A report commissioned by the National Council for

\footnotetext{
${ }^{1}$ We use the term 'teaching placement' to refer to the major independent teaching placements (known variously as 'teaching practicum', 'practical teaching placement', 'field experience', 'clinical practice', 'professional experience', or other terms)
} 
Accreditation of Teacher Education (NCATE, 2010) suggests that strengthening the "clinical practice' component of ITT programs "holds great promise for sparking improvement in P-12 learning and achievement" (p. 2). Preservice teachers need to develop knowledge of content, pedagogy, and child development, but critically, they also need to know how to apply their knowledge through professional practice. In their extensive study of the features of teacher preparation programs supplying new teachers to New York City schools, Boyd and colleagues (Boyd, Grossman, Lankford, Loeb, \& Wyckoff, 2009) found that exposure in ITT to the day-to-day work of teaching was a key feature that facilitated teachers' transition into first-year teaching. Preparing preservice teachers for the teaching placement is a 'high stakes' endeavour, with the potential to increase professional readiness more so than at any other stage of professional development (Caires et al., 2012). For ITT programs, it is essential that activities aimed at preparing preservice teachers for this "most important" component of teacher education (Anderson \& Stillman, 2012, p. 3) are systematically developed and evaluated.

Self-efficacy and classroom readiness. Preparation for teaching placements includes boosting preservice teachers' sense of self-efficacy and classroom readiness. Selfefficacy-domain-specific confidence-is defined as beliefs in one's capabilities to carry out the courses of action needed to achieve desired outcomes (Bandura, 1997). According to Bandura, self-efficacy plays a critical role in how well people manage challenging life experiences, and is formed through four sources: enactive experience, vicarious experience, verbal persuasion, and interpretation of physiological state. Self-efficacy for teaching has received considerable research attention, with results showing that higher levels of selfefficacy are associated with higher levels of teaching effectiveness (Klassen \& Tze, 2014). Self-efficacy can be assessed at varying levels of specificity and complexity, ranging from confidence to successfully complete particular activities (e.g., for preservice teachers their 'placement self-efficacy') to measures that assess multiple teaching-related activities (e.g., confidence for classroom management and student engagement). For preservice teachers, the self-efficacy to engage successfully in a teaching placement is affected by Bandura's hypothesized four sources, and in particular, by experiences with authentic teaching situations (enactive experience), exposure to successful models (vicarious experience), and constructive feedback (verbal persuasion) from experienced teachers.

One of the goals of teacher preparation programs is to develop preservice teachers' classroom readiness, or their multi-dimensional preparedness to engage in teaching tasks (e.g., Larsen, 2017). In this article, we focused on two kinds of classroom readiness. The first is a general sense of preparedness for upcoming teaching placements ('placement readiness'). The second is a multidimensional assessment of three key aspects of classroom readiness: emotional readiness (feeling positive about teaching), motivational readiness (feeling a motivational 'push' to start teaching), and cognitive readiness (feelings of readiness related to knowledge and skills). Emotional readiness addresses the positive (e.g., enthusiasm) and negative (e.g., anxiety) emotions that have been the subject of considerable recent research in education (e.g., Chen, 2019). Motivational readiness addresses variations in preservice teachers' eagerness to start teaching, or to see value in teaching as a career (see Watt \& Richardson's work on intrinsic career value, 2017). Finally, cognitive classroom readiness captures preservice teachers' perceptions of the knowledge and skills needed for success in the classroom (Paulick, Grosschedl, Harms, \& Möller, 2017). These three dimensions of classroom readiness reflect three of the core psychological processes relevant to preservice teachers' readiness to successfully engage in classroom teaching.

Scenario-based learning. Preservice teachers increase their self-efficacy and classroom readiness through learning experiences and actual engagement with authentic classroom situations. However, placing preservice teachers into 'real-life' teaching placements is a high-stakes endeavour: the consequences for the school and individual 
students in the classroom are high, and the emotional and professional costs to preservice teachers can be high if they enter the classroom when unprepared. In addition, teacher education programs face a reputational risk each time their preservice teachers begin their professional journey by entering schools to begin their teaching placement. One way to mitigate the risk of early 'live' classroom experiences is through engagement with simulated classroom experiences, such as those provided by scenario-based learning activities.

Scenario-based learning, also known as 'case-based learning' or 'near-world simulations' (Errington, 2011), engages participants in interactive scenarios that present authentic workplace experiences followed by a series of questions requiring the student to consider possible courses of action. Theories supporting SBL suggest that pedagogical knowledge cannot be simply transmitted to preservice teachers, but emerges from participation in the interactive social practices of schools and classrooms. For example, Lave and Wenger's (1991) situated learning theory suggests that preservice teacher learning is a function of the activity and context in which it occurs, with authentic experiences and social interaction a critical component of the learning process. In teacher education programs, attempts to professionally socialize preservice teachers may not be successful through direct instruction alone; research suggest that preservice teachers' values and beliefs are resistant to change in formal instructional settings, with field-based experiences providing more dynamic opportunities for reconceptualization of pre-existing beliefs and values (Korthagen, 2010). SBL can provide a situated learning experience that can contribute to cognitive growth, increased confidence to master challenging situations, and professional socialization (Hemphill, Richards, Gaudreault, \& Templin, 2015).

Other professions, especially in health-related fields such as medicine, dentistry, nursing, midwifery, and social work, have used and evaluated the efficacy of scenario-based learning for preservice training (often called 'case-based learning' [CBL] in these contexts). Cox and colleagues (Cox, Barron, Davis, \& de la Garza, 2017) showed that realistic clinical cases could link theory with practice and provide participants with authentic health-related experiences in a safe and non-threatening manner. Thistlewaite et al. (2012) reviewed 104 articles reporting evaluations of case-based learning in health fields, and found that, overwhelmingly, students (and teachers) enjoyed CBL and believed that it enhanced learning. Only a few studies have attempted to assess changes in students' knowledge or attitudes, with the overall finding that case-based learning seemed to foster effective learning in small groups, perhaps due to having structured learning activities closely linked to authentic clinical situations. McLean (2016) reviewed international use of CBL in health fields, and found the approach to be well-liked by students, but also to result in deeper student learning than alternative teaching methods.

The value of feedback and reflection. The effects of scenario-based learning activities can be enhanced by the inclusion of self-reflection and expert feedback (Anseel, Lievens, \& Schollaert, 2009), with the potential to increase self-efficacy, engagement, and retention (Brown et al., 2015). The reflective cycle of thinking about a challenging situation, weighing alternatives, and determining potential solutions requires reflective thought, but external feedback contributes to further examination of the action, and to a continuation of the cycle. When authentic experiences (including simulated experiences such as SBL) are followed by reflection and feedback, self-efficacy beliefs are influenced through three of the four self-efficacy sources: enactive experience (reflection on managing challenging situations), vicarious experience (observing how an experienced teacher manages a challenging situation), and verbal persuasion (receiving a message about your capabilities). For preservice teachers, activities that provide authentic classroom experiences in a lowstakes setting, coupled with opportunities for reflection and feedback could be a useful contribution to their preparation for classroom teaching.

\section{Current Study}


The purpose of this proof-of-concept study was to evaluate the feasibility and initial impact of an SBL intervention (including reflection and feedback components) designed to help prepare preservice teachers for the teaching placement in two different contexts. To our knowledge, this is one of the first studies to systematically explore the application of structured, scenario-based learning in teacher education. In Study 1 we administered the SBL activity to 40 preservice teachers at the start of their program in one primary-level ITT program in England, and collected data on participants' views of the utility of the activity, and how the activity influenced their placement self-efficacy and placement readiness. In Study 2 we administered a revised SBL activity to 151 preservice teachers in two universities in Australia prior to their second teaching placement. We used a quasi-experimental design to investigate teaching self-efficacy and classroom readiness, and assessed participants' placement self-efficacy and readiness using open-ended questions.

\section{Development of SBL Content for Studies 1 and 2}

As suggested by Fritzsche et al. (Fritzsche, Stagl, Salas, \& Burke, 2006), we adapted situational judgment test (SJT) content for the SBL activity. SJTs are controlled exercises or vignettes where an individual is presented with scenarios that are similar to those found in the actual workplace environment. Content for SJTs is developed using a critical incident technique in which experienced practitioners recall and elaborate specific past experiences that presented challenges or dilemmas in professional settings (e.g., Buyse \& Lievens, 2011). Cox et al. (2017) concluded that adapting SJTs for use in training situationssometimes called developmental SJTs — can be a useful way to build procedural and declarative knowledge in novices. A scenario-based activity based on SJT content can provide a relatively high-fidelity way to train judgment and decision-making for complex jobs (Fritzsche et al., 2006), while retaining the appeal of a low-stakes (i.e., low-risk) training environment. The scenarios were designed to help preservice teachers become more confident and skillful in dealing with uncertainty, especially in novel situations where choosing appropriate responses is difficult and ambiguous (Errington, 2011).

Development stages. The seven-stage development of the SJT scenarios originally created for the purpose of applicant selection included: (a) identifying target attributes on which the scenarios were built, (b) specifying scenario content (e.g., school levels, sociocultural context, scenario context, desired number of scenarios), (c) determining item type and response format, (d) creating and reviewing scenario content with a panel of experts using a critical incident technique (e.g., Buyse \& Lievens, 2011), (e) determining scoring keys with a group of experienced teachers and teacher educators, (f) administering prototype scenarios to preservice teachers for feedback, and ( $\mathrm{g}$ ) revising content and scoring based on iterative feedback. For a more detailed description of the multi-stage development of scenario content for SJTs (including the determination of the scoring key), please see Klassen, Kim, Rushby, and Bardach (2020).

Adaptation of the SJT item bank for SBL purposes involved choosing scenarios (the scoring of response options was already determined when the SJTs were developed), and generating scenario-specific expert feedback. Feedback messages were drafted and reviewed by six experienced teachers and teacher educators from the UK and Australia, with a consensus approach used to determine the final feedback messages. The SBL activity thus consisted of (a) classroom scenarios, (b) participant responses to scenario questions, (c) participant reflection on responses, and (d) tailored feedback from experts on participant responses.

\section{Study 1}

The purpose of Study 1 was to test the feasibility of the SBL activity and to assess placement self-efficacy, placement readiness, engagement in the SBL activity, and perceptions of the utility of the activity. We administered a brief (approximately 45-minutes) online SBL activity with six realistic classroom scenarios to preservice teachers in a UK 
primary ITT program in the northeast of England. For each of the six scenarios, participants rated the appropriateness of response options, reflected on their responses, received realtime feedback from experienced teachers, and responded to a series of questions about the SBL activity.

\section{Method}

Participants. The participants in Study 1 were 40 first-year preservice teachers $(72.5 \%$ female, mean age 24.3 years, $S D=4.06)$ at the start of a 1 -year postgraduate teacher education program. Participants were candidates who had recently been accepted into the ITT program, and had not yet completed a teaching placement.

Scenario-based learning activity. Participants were given the following instructions: In this scenario-based learning activity you will be presented with 6 realistic classroom scenarios followed by 3 possible response options. The activity consists of three tasks:

Task 1: Complete scenario responses. You will be asked to rate the appropriateness of each of the three response options in terms of what a beginning teacher working in a school should do (Inappropriate; Somewhat Inappropriate; Somewhat Appropriate; Appropriate) .

Task 2: Reflection. After you rate each option you will be asked to write a few sentences explaining the rationale behind your rating.

Task 3: Feedback. Once you have completed a question, you will be shown how most experienced teachers rated each option in the scenario. You will also be able to read the rationales provided by experienced teachers.

The SBL activity consisted of six text-based scenarios that reflected common classroom challenges, with scenario titles including: Teaching a mixed ability class, Managing competing deadlines, Dealing with angry parents, $A$ student is not coping with work, A difficult review meeting with mentor, and Student misbehaves in class. For an example of SBL content with reflection and feedback, please see Figure 1.

[Insert Figure 1 here]

After reading each scenario, participants rated the appropriateness of three response options (Rate the appropriateness of each of the options in terms of what a beginning teacher should do), and were asked to reflect on the reasons for their ratings. SBL scores were calculated by distance from expert ratings for each response (e.g., fully aligned $=3$ points; 1 away $=2$ points; 2 away $=1$ point; 3 away $=0$ points); expert feedback was delivered in real-time after the completion of each scenario. The highest possible score was 54 (6 scenarios $\times 3$ response options $\times 3$ maximum points).

Measures. In Study 1, we measured placement self-efficacy, placement readiness, task engagement, and utility of the intervention using three open-ended measures, each requiring a direct response (yes/somewhat/no) and an open-ended rationale. To assess placement self-efficacy, we asked Following the completion of this scenario-based learning activity, do you feel more or less confident about your teaching placement? Why or why not? To assess participants' placement readiness, we asked, Did this activity help you feel prepared for your first teaching placement? Why or why not? To assess perceptions of utility of the activity, we asked the following open-ended question, Did you think this was a useful learning activity? Please explain why. To assess engagement in the activity, we asked participants to rate six items (scored on a 1-6 scale) taken from previous participant reaction studies (e.g., Klassen et al., 2017), with items reflecting participants' level of engagement with the activity, e.g. I felt motivated to do my best on this activity, and The format of the activity was engaging $(\alpha=.74)$.

For Study 1 we report frequency of agreement scores (yes, somewhat, no) for the placement self-efficacy, placement readiness, and utility measures and also report frequency of three deductive codes for the open-ended responses. We coded the open-ended rationales for comments about (a) the reflection component of the SBL activity, (b) the 
feedback component of the SBL activity, and (c) the scenarios component of the SBL activity. Finally, we report scores from the six-item engagement scale.

\section{Results}

SBL activity. Scores on the SBL activity ranged from 39 to $50(M=43.80, S D=$ 2.77), with no significant differences for age or gender.

Placement self-efficacy. Nearly $90 \%$ of participants (87.5\%) stated that they felt more confident in entering the classroom after completing the SBL activity, with $12.5 \%$ rating their confidence as unchanged or lower as a result of the activity. Participants who reported an increase in their self-efficacy attributed the change to reflecting on professional practice (35\% of responses, e.g., I feel more confident because I have thought about things from a different, more professional perspective); value of feedback from experienced teachers (50\% of responses, e.g., I feel more confident because the detailed answers allowed me to understand how teachers cope with problems in the classroom in more depth), and exposure to realistic scenarios (15\% of responses, e.g., I feel more confident as it has made me aware of what could happen and how to address a situation).

Placement readiness. Over $90 \%(92.5 \%)$ of Study 1 participants stated that they felt more prepared after completing the SBL activity, with $7.5 \%$ rating their readiness as unchanged or lower. Participants who reported an increase in their placement readiness attributed the change to reflecting on professional practice $(24 \%$ of responses, e.g., It reinforced my judgement on how to be an effective professional in a learning environment); value of feedback from experienced teachers (32\% of responses, e.g., It was great to have feedback from experienced teaching staff on scenarios where you may be unsure how to react); and exposure to diverse and realistic scenarios (43\% of responses, e.g., I know when I am on placement I will struggle with scenarios such as these).

Utility of the SBL activity. Of the 40 participants, $95 \%$ of participants rated the SBL activity as a useful learning activity, with two participants rating the activity as not useful. We analysed the open-ended utility responses according to the three elements of the SBL activity: responses were coded for attributions to (a) reflection, (b) feedback, and (c) authenticity of scenarios. Of the total responses, $40 \%$ indicated that the activity provided a useful opportunity for reflection (e.g., Yes, it was an important task. I had to use my knowledge, I could then see my own strengths and weaknesses in my teaching methods. It was very beneficial to see, I took a lot away from this task); $33 \%$ of responses indicated that the feedback from experienced teachers was useful (e.g., Seeing other teachers' responses to various situations has improved my knowledge on how to handle difficult situations), and $26 \%$ of responses indicating that the opportunity to encounter authentic teaching dilemmas was useful (e.g., The scenarios do help you understand the variety of situations that you may have to deal with and how to achieve the best outcome). Participants that were less favourably disposed towards the activity commented that more explanation may be needed to understand and that the scenarios generally felt artificial and do not reflect the fact that these decisions need to be made much quicker (when teaching).

Engagement measure. Participants' mean score on the 6-point engagement scale was $M=5.30(S D=.56)$, with a range of 3.33 to 6.00 , and with Cronbach's $\alpha=.74$.

\section{Brief Discussion}

In Study 1 we saw that most new trainee teachers reported that the SBL activity played a role in increasing their teaching self-efficacy, their readiness to enter the classroom, and that they had generally favourable impressions of the usefulness of the SBL activity. Although the intervention was brief and the outcomes were all self-report, the results from Study 1 suggested that an SBL activity could be a valuable activity to expose new preservice teachers to challenging classroom situations and to encourage reflection about the situations and decisions that they will face when they enter the classroom on teaching placements.

\section{Study 2}


The purpose of Study 2 was to trial the SBL activity in a different context, to gauge participant reactions to the activity, and to explore the relation of the activity with reported self-efficacy and classroom readiness. In Study 2 we administered six SBL scenarios (different from those in Study 1 and checked and adapted to Australian context by four Australian researchers familiar with the New South Wales education system) to 151 preservice teachers in two universities in New South Wales, Australia. Most participants in Study 2 had previously completed a 'minor' school placement and were preparing for their 'major' school placement.

The following research questions were addressed: Does the SBL activity affect preservice teachers' self-efficacy, and emotional, motivational, and cognitive classroom readiness? We assumed that the intervention would lead to an increase in teaching selfefficacy (Hypothesis 1) emotional classroom readiness (Hypothesis 2), motivational classroom readiness (Hypothesis 3), and cognitive classroom readiness (Hypothesis 4). We also addressed the questions: How do preservice teachers rate their placement self-efficacy and placement readiness after completing the SBL activity? We hypothesized that most participants would agree that the SBL activity increased placement self-efficacy (Hypothesis 5) and placement readiness (Hypothesis 6).

\section{Method}

Procedure. Study 2 was conducted at two university-based ITT programs in Australia as part of a 'hurdle requirement' (i.e., compulsory but not assessed) that preservice teachers completed before starting their major teaching placement. Participants completed the activity on their own device at home, and no compensation for participation was provided.

Participants were randomly assigned to an intervention group and a control group in which the timing of the questionnaire measures varied: The control group completed the teachers' self-efficacy and classroom readiness outcome measures prior to working on the SBL activity, whereas the intervention group completed the outcome measures questionnaire after the SBL activity. This design enabled us to draw conclusions on the effects of the intervention while also allowing all participants to receive the SBL activity in the same session. Both groups completed the open-ended placement self-efficacy and placement readiness items after completing the scenarios (see Study 1 for details).

Figure 2 displays a schematic diagram of the experimental design for Study 2. First, all preservice teachers filled out a questionnaire asking for key socio-demographic information. The control group then worked on the questionnaire comprising all outcome measures (teaching self-efficacy, emotional, motivational, and cognitive classroom readiness). After that both the control group and the intervention group worked on the SBL activity and completed the open-ended items. As a manipulation check, the SBL activity was followed by two questions asking preservice teachers whether they (a) read all the feedback of the expert teachers, (b) had done their best in the reflection exercise. These questions were included to check whether some participants might not have taken the SBL activity seriously (see Participants section for more details).

[Insert Figure 2 here]

Participants. 151 preservice teachers gave consent to the use of their data for research purposes (over $90 \%$ of possible participants). Participants reported to program leaders that the SBL activity was administered at an especially busy time in the academic calendar (personal correspondence with program leader, 29.05.20); as a result, compliance with the activity was lower than expected. A total of 20 participants of the intervention group who had indicated that they did not carefully read the feedback or did not work seriously on the reflection exercise ('manipulation check questions') were excluded from the comparative analyses because feedback and reflection were the core features of the intervention. Due to excluding these participants from the intervention group, the effects should therefore be interpreted as effects of the intervention given that participants had taken the intervention 
seriously. Please note that it was not necessary to exclude participants from the control group, as they had responded to the outcome measures prior to working on the scenarios. The resulting final sample consisted of 131 preservice teachers (68 in the control group and 63 the intervention group). The preservice teachers were on average 25.20 years old ( $S D=$ 6.01 ) and $58.0 \%$ identified as females. The participants came from two university-based teacher education providers (one city and one regional) in New South Wales, Australia. Descriptive information separately for the intervention and control group can be found in Table 1.

[Insert Table 1 here]

Scenario-based learning activity. The SBL activity consisted of six scenarios, with the following titles: Teacher juggling multiple tasks, Professionalism is compromised, Student doesn't speak English, Peer asks for advice, Managing extra-curricular activities, and Dealing with unresponsive class. The six scenarios with scoring key had been developed, pilot-tested, and revised using the seven-stage process described in Klassen et al., 2017.

Measures. The measures in Study 2 included teaching self-efficacy, classroom readiness, a set of control variables, plus open-ended measures of placement self-efficacy and placement readiness (e.g., Following the completion of this SBL activity, do you feel more or less confident about your teaching placement?).

Teaching self-efficacy. We assessed teaching self-efficacy with a three-item scale adapted from the Teachers' Sense of Efficacy Scale (Tschannen-Moran \& Woolfolk Hoy, 2001), and used by Klassen and Durksen (2014). An example item is 'I am confident that I can manage student behaviour', with reliabilities (Cronbach alpha) $\alpha_{\text {Control Group }}=.83$; $\alpha_{\text {Intervention }}$ Group $=.77$ ).

Classroom readiness. To assess classroom readiness, we relied on items from existing scales (Frenzel et al., 2016; Klassen, Yerdelen, \& Durksen, 2013; Schiefele, Streblow, \& Retelsdorf, 2013) as well as self-developed items to map preservice teachers' perceived classroom readiness in three domains: emotional domain (two items, sample item: I feel enthusiastic when thinking about becoming a teacher, $\alpha_{\mathrm{CG}}=.89 ; \alpha_{\mathrm{IG}}=.88$ ), motivational domain (two items, sample item: I am motivated to start teaching as soon as possible, $\alpha_{\mathrm{cG}}=$ $.77 ; \alpha_{1 G}=.77$ ), cognitive domain (two items, sample item: I think I have the knowledge needed to be a good teacher, $\alpha_{\mathrm{CG}}=.67 ; \alpha_{\mathrm{IG}}=.83$ ).

Control variables. The following control variables were used: preservice teachers' age, year of study, gender $(0=$ female, $1=$ male $)$, prior experience working in schools $(0=$ no, 1 = yes). We included these variables to control for sociodemographic characteristics that have been shown to be related to our outcomes in previous studies (e.g., effects of gender and teaching experience on self-efficacy, see Huang, 2013; Klassen \& Chiu, 2010). As another SBL study (with different content and a different design) had already taken place at these sites, the participating preservice teachers were asked whether they had participated in this study. Prior participation was used as a further control variable $(0=\text { no, } 1=\text { yes })^{2}$.

Placement self-efficacy. We used an open-ended question which included a direct response (yes/somewhat/no) about placement self-efficacy: Following the completion of this scenario-based learning activity, do you feel more or less confident about your teaching placement? Why or why not?

Placement readiness. We used an open-ended question which included a direct response (yes/somewhat/no) about placement readiness: Did this activity help you feel prepared for your first teaching placement? Why or why not?

\section{Analysis}

\footnotetext{
${ }^{2}$ Three participants indicated that they could not remember whether they had already participated. Their response to this question was therefore coded as missing data (see 'Analyses' for information regarding missing data).
} 
To investigate the effects of the scenario-based learning activity on teaching selfefficacy and three dimensions of classroom readiness, we estimated a path model using Mplus Version 8.2 (Muthén \& Muthén, 2017) with the robust maximum likelihood estimator (MLR) in conjunction with full information maximum likelihood estimation (FIML) to handle missing data. There was no missing data present at the item level, with two exceptions: $0.8 \%$ missing data for gender and $2.3 \%$ missing data on the question asking participants whether they had already participated in a similar study.

The effects of the intervention on the outcomes (self-efficacy, three domains of classroom readiness) were estimated using a dummy-coded variable indicating whether participants had been part of the control or the intervention group $(0=$ control group, $1=$ intervention group). We ran the analyses both with and without the inclusion of control variables and reported both results. Standardized and unstandardized regression coefficients are shown, and the standardized estimates can be interpreted according to Cohen's (1988) guidelines with values above .10 indicating small effects, values above .30 indicating moderate effects, and values above .50 indicating large effects. All significance testing was performed at the .05 level.

We calculated relative frequencies of agreement (yes, no, somewhat) for the openended placement self-efficacy and placement readiness items, and coded the open-ended responses for attributions to (a) reflections about teaching, (b) feedback from professionals, and (c) experiencing realistic classroom situations.

\section{Results}

Scores on the SBL activity ranged from 38-49 (maximum score possible $=54$ ), with a mean of $43.52(S D=2.30)$. Descriptive information and correlations among the variables used to test the effectiveness of the intervention on teaching self-efficacy and three dimensions of classroom readiness can be consulted in Table 1. In this results section, we present results from the path model and the descriptive analysis of the open-ended placement self-efficacy and placement readiness items.

\section{[Insert Table 1 here]}

Effects of the intervention on teaching self-efficacy and classroom readiness. Even though all means were higher in the intervention than in the control group (see Table 1 ), the differences were not large, and we did not obtain a statistically significant intervention effect for self-efficacy (Hypothesis $1 ; \beta=0.11, p=.27$ ), for motivational classroom readiness (Hypothesis 3; $\beta=0.10, p=.30$ ), or for cognitive classroom readiness (Hypothesis $4 ; \beta=$ $0.04, p=.42$ ) in the path model. However, the results showed that the intervention had a statistically significant effect on emotional classroom readiness (supporting Hypothesis 2), indicating that participating in the intervention increased preservice teachers' emotional classroom readiness $(\beta=0.31, p=.03)$.

The findings remained robust to including a set of control variables. Also in the second model with covariates, self-efficacy was not statistically significantly affected by the intervention $(\beta=0.11, p=.28)$. The intervention had a statistically significant effect on emotional classroom readiness $(\beta=0.31, p=.03)$, and no statistically significant effects on motivational and cognitive classroom readiness $(\beta=0.09, p=.31$, and $\beta=0.03, p=.43$, respectively). No statistically significant effects were found for the control variable gender (female $=0$, male $=1$; for self-efficacy: $\beta=0.18, p=.310$; for emotional classroom readiness: $\beta=-0.12, p=.53$; for motivational classroom readiness: $\beta=-0.20, p=.27$; for cognitive classroom readiness, $\beta=0.05, p=.80$ ). Similarly, there were no statistically significant effects for age on self-efficacy $(\beta=0.07, p=.44)$, emotional classroom readiness $(\beta=-0.03$, $p=.63)$, motivational classroom readiness $(\beta=-0.16, p=.75)$, and cognitive classroom readiness $(\beta=0.02, p=.84$ ) emerged. The same pertained to year of study (for self-efficacy: $\beta=-0.07, p=.49$; for emotional classroom readiness: $\beta=-0.05, p=.59$; for motivational classroom readiness: $\beta=-0.17, p=.09$; for cognitive classroom readiness: $\beta=-0.11, p=$ 
.33). Prior experience was statistically significantly related to self-efficacy ( $\beta=0.51, p=.04$ ), but not to the classroom readiness domains (for emotional classroom readiness: $\beta=0.17, p$ $=.51$; for motivational classroom readiness: $\beta=-0.01, p=.98$; for cognitive classroom readiness: $\beta=.39, p=.20$ ). Having already participated in a another SBL study did not statistically significantly predict any of the outcomes (for self-efficacy: $\beta=0.07, p=.73$; for emotional classroom readiness: $\beta=0.26, p=.18$; for motivational classroom readiness: $\beta=$ $0.07, p=.72$; for cognitive classroom readiness: $\beta=0.06, p=.80$ ). Table 2 reports all effects (unstandardized effects including standard deviations and standardized effects) of the model with covariates.

Placement self-efficacy. On the single-item measure of placement self-efficacy, $68 \%$ of participants stated that they felt more confident about starting their placement after completing the SBL activity (Hypothesis 5), whereas 30\% reported that the activity did not affect their confidence one way or the other, and $2 \%$ reported that they felt less confident. Similar to Study 1 , the rationales provided for placement self-efficacy ratings were categorised as relating to (a) reflection on own responses, (b) consideration of feedback from experienced teachers, and (c) reflection on the scenario content. Of the participants who offered a rationale behind their placement self-efficacy ratings, $19 \%$ of the explanations related to the value of reflecting on their own responses (e.g., It forced me to reflect on my professional responses to situations), $25 \%$ of responses related to the feedback from experienced teachers (e.g., I feel more confident because a lot of my responses aligned with those of experienced teachers), and $17 \%$ noted the value of exposure to authentic scenarios (e.g., I know now how to better approach some scenarios I will likely experience).

Reasons for the lack of change in confidence centered on the lack of impact of an online assessment (I don't see how an online quiz could increase confidence, and I will only feel more confident about my teaching placement once l've practiced teaching more), along with comments about (too heavy) workload and (poor) timing of the SBL exercise during the ITT program. Although only a small number of participants $(2 \%)$ reported experiencing less confidence after completing the SBL activity, their comments were revealing: e.g., I'm less confident, but in a good way. I am now more aware of the issues involved in working in a school; I feel slightly less confident; most of my answers and rationales lined up with the feedback, but some things didn't, so it's clear I still have plenty to learn.

Placement readiness. In Study $2,72 \%$ of participants stated that they felt more prepared after completing the scenarios (Hypothesis 6), with $28 \%$ rating their confidence as unchanged as a result of the activity. Participants who reported an increase in their selfefficacy attributed the change to reflecting on professional practice $(42 \%$ of responses, e.g., Yes, because it made me consider what my strengths and weaknesses as a teacher may be); value of feedback from experienced teachers (17\% of responses, e.g., Yes, it has been like speaking with an experienced teacher about common situations and what is or is not acceptable as a course of action), and exposure to realistic scenarios (42\% of responses, e.g., Yes, considering real life scenarios helped me get in the right mindset for my upcoming practicum).

For those who rated their placement readiness as unchanged, rationales focused on the (lack of) intensity of the SBL activity (e.g., There were only a few scenarios, and I feel as though 'textbook' scenarios are always so different from what happens in real life).

\section{Brief Discussion}

In Study 2 we administered the SBL activity in a different setting (Australia) and to preservice teachers who had already completed a minor teaching placement. Using a quasiexperimental design, we found that although mean scores in the intervention group were slightly higher for teaching self-efficacy and the three classroom readiness domains, the differences were statistically significant only for emotional classroom readiness. Results from the open-ended placement self-efficacy and placement readiness measures showed that 
most participants felt more confident and prepared to enter the classroom after completing the SBL activity, although the positive impact of the intervention was less marked than in Study 1 , where participants had not completed any of their teaching placements.

\section{General Discussion}

For prospective teachers, the teaching placement is a critical developmental test, with the likelihood that the placement will bring about unforeseen challenges that need to be faced with good judgement, reflective practice, and support and feedback from experienced mentors. An SBL intervention that is built on thoroughly-tested, authentic classroom scenarios has the potential not only to expose preservice teachers to a wide range of novel and challenging situations, but to encourage reflection and integration of their own thinking with that of more experienced mentors. We found that although most participants in both studies found the SBL activities useful in boosting their confidence and in preparing them for their upcoming placements, the less experienced preservice teachers were more likely to report that the activity boosted their placement self-efficacy and readiness than those participants who had already completed a teaching placement.

For almost $90 \%$ of participants in Study 1 , and $68 \%$ of participants in Study 2, the SBL activity was reported to positively influence how confident participants felt about carrying out the tasks expected in the teaching placement. From a self-efficacy perspective, the rationales provided for increased confidence mapped well onto three of the four sources of self-efficacy, with remarks about how the range of scenarios, coupled with opportunities for reflection (i.e., enactive experience), plus feedback from experienced teachers (i.e., verbal persuasion and modelling) increased their confidence in facing the challenges expected in the placement. The same effect was not so clearly seen in the three-item self-efficacy scale, with a non-significant difference in self-efficacy levels between the control and intervention groups. One explanation for this might be the differences in correspondence of the two types of self-efficacy measures with the SBL activity, with one measure (placement self-efficacy) directly referring to the SBL activity, whereas the measure of teaching self-efficacy did not show the same direct connection with the SBL activity. In addition, it may be that exposure to realistic (i.e., challenging and ambiguous) scenarios do not automatically increase preservice teachers' self-efficacy beliefs, but rather increase the awareness of the challenges without raising teaching self-efficacy.

Differences in the degree of endorsement about placement self-efficacy (Study 1 $87.5 \%$ reported more confidence versus $68 \%$ in Study 2 ) and placement readiness $(92.5 \%$ in Study 1 versus $72 \%$ in Study 2) between the two samples raise questions about how an SBL activity might be adapted to support the developmental trajectory of preservice teachers at different stages. Professional identity develops over time during pre-professional training, and is dependent on the quality of support and instruction (Caires et al., 2012), alongside exposure to professional experiences. This exposure to professional contexts may be more important than ever; the requirement for previous school experience has recently been dropped from the entry requirements for ITT programmes in England (DfE, 2020). For preservice teachers who are at the beginning of their professional development and have had limited experience in a classroom setting, exposure to an SBL intervention with opportunity for reflection and for feedback may be particularly welcomed, even if the classroom scenarios are relatively brief and uncomplicated. For more experienced preservice teachers, it may be beneficial to consider scenarios that deliver more sophisticated and complex scenarios and challenges, potentially using a 'branching' approach which increases complexity and authenticity of participant experience and that may also increase engagement in the activity (e.g., Reddock, Auer, \& Landers, 2020).

It is clear from the results of this study that more work is needed to show how SBL activities have an effect on preservice teachers' self-efficacy and classroom readiness; when, an SBL intervention would optimally be implemented; and who especially might benefit from 
such an intervention. We know from recent research that scenarios + reflection + feedback provide a more potent intervention for preservice teachers than interventions without these three components (Authors, anonymised), but we do not yet know about how these elements act on participants' beliefs and professional readiness. In terms of the timing of the intervention, we have learned that 'new' preservice teachers place a high value on an SBL activity that exposes them to realistic classroom situations, whereas preservice teachers with some classroom experience were more judicious in their endorsement of the activity. However, we do not yet know if such an intervention has lasting effects for any group of preservice teachers, and we do not know how a more powerful intervention-administered over a longer period of time-might promote longer-term growth in self-efficacy and readiness.

The addition of a structured live or online discussion group led by mentors would provide participants with the opportunity to discuss ambiguities and uncertainties uncovered in the online activity, and to consider multiple perspectives on the issues that arose during the SBL intervention. A more clear focus on the key attributes targeted in the scenarios (e.g., clustering scenarios by key construct, e.g., adaptability, or communication) may prove useful to include in future iterations of SBL interventions, and extending the intervention beyond a single session to enhance the impact of SBL activities is clearly warranted.

Limitations of the study. The sample in Study 1 was relatively small, but it provided a useful setting in which to test a prototype in order to investigate the feasibility of the SBL activity. Further work is needed to understand the longer-term impact of the intervention, and a longitudinal design with multiple intervention phases is more likely to have a lasting impact on self-efficacy and classroom readiness. Our one-shot intervention suggested that most preservice teachers perceived that the SBL activity increased their placement self-efficacy and preparedness to enter the classroom, but we don't know if those perceptions translate into changed behaviours and improved outcomes in teacher effectiveness and student learning. In addition, the SBL activity was not well integrated into the curriculum, and a follow-up seminar may help consolidate any professional learning that took place during the activity. Further work is needed to test the individual elements of the activity, i.e., to understand how the scenarios, reflection, and feedback interact to shape self-efficacy and readiness.

\section{Conclusions}

For preservice teachers, 'reality shock' is an all-too-frequent consequence of a preservice teachers' first encounter (from the teacher's perspective) with classroom challenges (Dicke, Elling, Schmeck, \& Leutner, 2015). Scenario-based learning approaches have the potential to introduce preservice teachers to the culture of the workplace, achieve graduate standards, develop their professional identity, and to increase the confidence and preparedness for the teaching placement and for subsequent professional practice. The efficiency of the delivery of online SBL activities is appealing, with authentic classroom scenarios delivered to large numbers of trainees simultaneously, and with feedback from experienced teachers available to all participants in real time. The results from these two studies show that an SBL activity can play an important role in preparing preservice teachers for their school placements. 


\section{References}

Anderson, L. M., \& Stillman, J. A. (2012). Student teaching's contribution to preservice teacher development: A review of research focused on the preparation of teachers for urban and high-needs contexts. Review of Educational Research, 83, 3-69.

Anseel, F., Lievens, F., \& Schollaert, E. (2009). Reflection as a strategy to enhance task performance after feedback. Organizational Behavior and Human Decision Processes, 110, 23-35.

Authors, anonymised

Bandura, A. (1997). Self-efficacy: The exercise of control. Freeman.

Boyd, D. J., Grossman, P. L., Lankford, H., Loeb, S., \& Wyckoff, J. (2009). Teacher preparation and student achievement. Educational Evaluation and Policy Analysis, 31, 416-440.

Brown, A. L., Lee, J., \& Collins, D. (2015). Does student teaching matter? Investigating preservice teachers' sense of efficacy and preparedness. Teaching Education, 26, 77-93.

Buyse, T., \& Lievens, F. (2011). Situational judgment tests as a new tool for dental student selection. Journal of Dental Education, 75, 743-749.

Caires, S., Almeida, L., \& Vieira, D. (2012). Becoming a teacher: student teachers' experiences and perceptions about teaching practice. European Journal of Teacher Education, 35, 163-178.

Chen, J. (2019). Efficacious and Positive Teachers Achieve More: Examining the Relationship Between Teacher Efficacy, Emotions, and Their Practicum Performance. The Asia-Pacific Education Researcher, 28(4), 327-337.

Cox, C. B., Barron, L. G., Davis, W., \& de la Garza, B. (2017). Using situational judgment tests (SJTs) in training: Development and evaluation of a structured, low-fidelity scenario-based training method. Personnel Review, 46, 36-45.

DfE (2020). Initial teacher training: criteria and supporting advice. Retrieved from: https://www.gov.uk/government/publications/initial-teacher-training-criteria/initialteacher-training-itt-criteria-and-supporting-advice

Dicke, T., Elling, J., Schmeck, A., \& Leutner, D. (2015). Reducing reality shock: The effects of classroom management skills training on beginning teachers. Teaching and Teacher Education, 48, 1-12.

Errington, E. P. (2011). Mission possible: Using near-world scenarios to prepare graduates for the professions. International Journal of Teaching and Learning in Higher Education, 23, 84-91.

Frenzel, A.C., Pekrun, R., Goetz, T., Daniels, L.M., Durksen, T.L., Becker-Kurz, B., \& Klassen, R.M. (2016). Measuring teachers' enjoyment, anger, and anxiety: The Teacher Emotions Scales (TES). Contemporary Educational Psychology, 46, 148-163.

Fritzsche, B. A., Stagl, K. C., Salas, E., \& Burke, C. S. (2006). Enhancing the design, delivery, and evaluation of scenario-based training: Can situational judgment tests contribute? In J. A. Weekley \& R. E. Ployhart (Eds.), Situational judgment tests: theory, measurement and application (pp. 301-318). Lawrence Erlbaum: Mahwah, New Jersey.

Goldhaber, D., Krieg, J. M., \& Theobald, R. (2017). Does the match matter? Exploring whether student teaching experiences affect teacher effectiveness. American Educational Research Journal, 54, 325-359.

Hemphill, M. A., Richards, K. A., Gaudreault, K. L., \& Templin, T. J. (2015). Pre-service teacher perspectives of case-based learning in physical education teacher education. European Physical Education Review, 21, 432-450.

Huang, C. (2013). Gender differences in academic self-efficacy: a meta-analysis. European Journal of Psychology of Education, 28(1), 1-35.

Klassen, R. M., \& Chiu, M. M. (2010). Effects on teachers' self-efficacy and job satisfaction: Teacher gender, years of experience, and job stress. Journal of Educational Psychology, 102(3), 741.

Klassen, R. M., \& Durksen, T. L. (2014). Weekly self-efficacy and work stress during the final teaching practicum: A mixed methods study. Learning and Instruction, 33, 158-169.

Klassen, R. M., Durksen, T. L., Kim, L. E., Patterson, F., Rowett, E., Warwick, J., Warwick, P., \& Wolpert, M. A. (2017). Developing a proof-of-concept selection test for entry into 
primary teacher education programs. International Journal of Assessment Tools in Education, 4, 96-114.

Klassen, R. M., Kim, L. E., Rushby, J. V., \& Bardach, L. (2020). Can we improve how we screen applicants for initial teacher education? Teaching and Teacher Education, 87, 102949.

Klassen, R. M., \& Tze, V. M. C. (2014). Teachers' self-efficacy, personality, and teaching effectiveness: A meta-analysis. Educational Research Review, 12, 59-76.

Klassen, R. M., Yerdelen, S., \& Durksen, T. L. (2013). Measuring Teacher Engagement: Development of the Engaged Teachers Scale (ETS). Frontline Learning Research, 1, 33-52.

Korthagen, F. A. J. (2010). Situated learning theory and the pedagogy of teacher education: Towards an integrative view of teacher behavior and teacher learning. Teaching and Teacher Education, 26, 98-106.

Larsen, E. (2017). Developing Professional Learner Identities: A Critical Piece in the Classroom Readiness Puzzle. In Teacher Education Policy and Practice (pp. 17-34). Springer, Singapore.

Lave, J., \& Wenger, E. (1991). Situated learning: Legitimate peripheral participation. Cambridge: Cambridge University Press.

McLean, S. F. (2016). Case-based learning and its application in medical and health-care fields: A review of worldwide literature. Journal of Medical Education and Curricular Development,

Muthén, L.K., \& Muthén, B.O. (1998-2017). Mplus User's Guide: Statistical Analysis with Latent Variables (7th ed.). Los Angeles, CA: Muthén \& Muthén.

National Council for Accreditation of Teacher Education (2010). Transforming teacher education through clinical practice: A national strategy to prepare effective teachers. ERIC Clearinghouse.

Paulick, I., Großschedl, J., Harms, U., \& Möller, J. (2016). Preservice teachers' professional knowledge and its relation to academic self-concept. Journal of Teacher Education, 67(3), 173-182.

Reddock, C. M., Auer, E. M., \& Landers, R. N. (2020). A theory of branched situational judgment tests and their applicant reactions. Journal of Managerial Psychology. DOI 10.1108/JMP-10-2018-0434

Ronfeldt, M. (2015). Field placement schools and instructional effectiveness. Journal of Teacher Education, 66, 304-320.

Schiefele, U., Streblow, L., \& Retelsdorf, J. (2013). Dimensions of teacher interest and their relations to occupational well-being and instructional practices. Journal for Educational Research Online, 5(1), 7-37.

Thistlethwaite, J. E., Davies, D., Ekeocha, S., Kidd, J. M., MacDougall, C., Matthews, P., Purkis, J., \& Clay, D. (2012). The effectiveness of case-based learning in health professional education. A BEME systematic review. Medical Teacher, 34, e421-e444.

Tschannen-Moran, M., \& Woolfolk Hoy, A. (2001). Teacher efficacy: Capturing an elusive construct. Teaching and Teacher Education, 17, 783-805.

Watt, H. M., \& Richardson, P. W. (2007). Motivational factors influencing teaching as a career choice: Development and validation of the FIT-choice scale. Journal of Experimental Education, 75(3), 167-202.

Wideen, M., Mayer-Smith, J., \& Moon, B. (1998). A critical analysis of the research on learning to teach: Making the case for an ecological perspective on inquiry. Review of Educational Research, 68, 130-178. 
Table 1

Descriptive Statistics, and Bivariate Correlations Among All Variables Separately for the Intervention and Control Group

\begin{tabular}{|c|c|c|c|c|c|c|c|c|c|}
\hline Variable & 1. & 2. & 3. & 4. & 5. & 6. & 7. & 8. & 9. \\
\hline 1. Self-efficacy & & .46 & .36 & .56 & .09 & .45 & -.04 & .04 & .12 \\
\hline 2. Emotional CR & .64 & & .77 & .48 & -.16 & .09 & -.02 & -.11 & .16 \\
\hline 3. Motivational CR & .55 & .80 & & .43 & -.10 & .13 & -.17 & -.38 & .07 \\
\hline 4. Cognitive CR & .69 & .76 & .58 & & -.03 & .46 & -.01 & -.10 & .03 \\
\hline 5. Age & .04 & .09 & .08 & .06 & & .53 & -.28 & -.01 & -.09 \\
\hline 6. Gender & -.24 & -.37 & -.45 & -.38 & .07 & & .03 & -.09 & .02 \\
\hline 7. Years of Study & .05 & -.14 & -.16 & -.13 & -.28 & .09 & & .45 & -.41 \\
\hline 8. Prior experience & .34 & .25 & .19 & .33 & -.43 & -.29 & .24 & & -.24 \\
\hline 9. Prior part. & -.06 & .17 & .16 & .07 & .23 & .15 & -.55 & -.16 & \\
\hline M & $4.74 / 4.80$ & $4.90 / 5.20$ & $5.00 / 5.09$ & $5.02 / 5.05$ & $24.94 / 25.48$ & $0.45 / 0.38$ & $3.09 / 3.24$ & $0.82 / 0.79$ & $0.62 / 0.58$ \\
\hline SD & $0.63 / 0.64$ & $0.93 / 0.82$ & $0.88 / 0.97$ & $0.64 / 0.75$ & $5.57 / 6.49$ & - & $1.70 / 1.48$ & - & - \\
\hline
\end{tabular}

Note. Correlations for the Control Group are in the Upper Diagonal and Correlations for the Intervention Group; Descriptive statistics displayed in the following order: Control group, intervention group 1; CR = Classroom Readiness; Dummy-coded variables were used for gender $(0=$ female, $1=$ male $)$, prior experience working in schools $(0=$ no prior experience, $1=$ prior experience $)$, and prior participation in a SBL study $(0=$ no, $1=$ yes $)$; Statistically significant correlations at $p<.05$ are boldface. 
Table 2

Results of the Path Model: Effects of the Intervention on Self-efficacy, Emotional Classroom Readiness, Motivational Classroom Readiness, and Cognitive Classroom Readiness

\begin{tabular}{|c|c|c|c|c|c|c|c|c|}
\hline \multirow{2}{*}{ Predictors } & \multicolumn{2}{|c|}{ Self-efficacy } & \multicolumn{2}{|c|}{ Emotional CR } & \multicolumn{2}{|c|}{ Motivational CR } & \multicolumn{2}{|c|}{ Cognitive CR } \\
\hline & Est. (SE) & Std. Est. & Est. (SE) & Std. Est. & Est. (SE) & Std. Est. & Est. (SE) & Std. Est. \\
\hline Effect Intervention & $0.07(0.11)$ & 0.11 & $0.27(0.15)$ & 0.31 & $0.08(0.12)$ & 0.09 & $0.02(0.12)$ & 0.03 \\
\hline Controls: Age & $0.01(0.01)$ & 0.07 & $-0.01(0.01)$ & -0.04 & $-0.01(0.02)$ & -0.03 & $0.00(0.01)$ & 0.02 \\
\hline Controls: Gender & $0.12(0.12)$ & 0.18 & $-0.10(0.16)$ & -0.12 & $-0.18(0.17)$ & -0.20 & $0.03(0.12)$ & 0.05 \\
\hline Controls: Years of Study & $-0.03(0.04)$ & -0.07 & $-0.03(0.05)$ & -0.05 & $-0.10(0.06)$ & -0.17 & $-0.05(0.05)$ & 0.11 \\
\hline Controls: Prior experience & $0.32(0.16)$ & -0.51 & $0.15(0.23)$ & 0.17 & $-0.01(0.23)$ & -0.01 & $0.27(0.22)$ & 0.39 \\
\hline Controls: Prior participation & $0.04(0.13)$ & 0.07 & $0.23(0.17)$ & 0.26 & $0.07(0.18)$ & 0.07 & $0.04(0.15)$ & 0.06 \\
\hline
\end{tabular}

Note. $\mathrm{CR}=$ Classroom readiness $;$ Est. = unstandardized estimate; Std. Est. = standardized estimate; Dummy-coded variables were used for gender $(0=$ female, $1=$ male $)$, prior experience working in schools $(0=$ no experience, $1=$ prior experience $)$, and prior participation in an $S B L$ study $(0=$ no, $1=$ yes $)$; One-tailed tests were conducted for the intervention effects and two-tailed tests were conducted for the control variables; Statistically significant results at $p$ $<.05$ are boldface. 
Figure 1. Example of SBL Activity and Feedback

While on school break time duty, you see a group of students taunting another student, Meena. Before you can intervene, Meena aggressively swears at the other students in retaliation. At that moment, a senior teacher, Mr Ross, exits the school building and overhears Meena swearing. As he only sees this part of the situation, Mr Ross begins to reprimand Meena for swearing at the other students.

Rate the appropriateness of each of the options in terms of what a beginning teacher should do (Inappropriate; Somewhat Inappropriate; Somewhat Appropriate; Appropriate)

Option A:

Somewhat Somewhat
Inappropriate inappropriate appropriate Appropriate

Allow Mr Ross to continue to reprimand Meena, then explain the entire incident

to him afterwards

(1)

Please briefly explain the rationale behind your response to Option $\mathrm{A}$

It may come across as rude to interrupt Mr Ross, a senior teacher, but, as a colleague, he would probably expect me to say something as I witnessed the event that led to the retaliation.

\footnotetext{
You thought Option A was somewhat inappropriate.

Your rationale: It may come across as rude to interrupt Mr Ross, a senior teacher, but, as a colleague, he would expect me to say something as I witnessed the event that led to the retaliation.

Experienced teachers also rated this option as somewhat inappropriate.

Even though it may seem unprofessional to interrupt Mr Ross, it's important that you share your observations of the entire incident so Mr Ross can deal with the whole incident appropriately and fairly.
}

If your rating was directly aligned with how the majority of experienced teachers rated the option, as in this example, your response would be highlighted in light green.

If your rating was one away from the majority of experienced teachers' ratings (for instance, if you rated the option as inappropriate but most experienced teachers rated it as somewhat inappropriate) it would be highlighted in dark green.

If your rating was two away from most experienced teachers' ratings (for example, if you rated the option as appropriate but most experienced teachers rated it as somewhat inappropriate) it would be highlighted in light orange.

If your rating was three away from most experienced teachers' ratings (for example, if you rated the option as appropriate but most experienced teachers rated it as inappropriate) it would be highlighted in dark orange. 


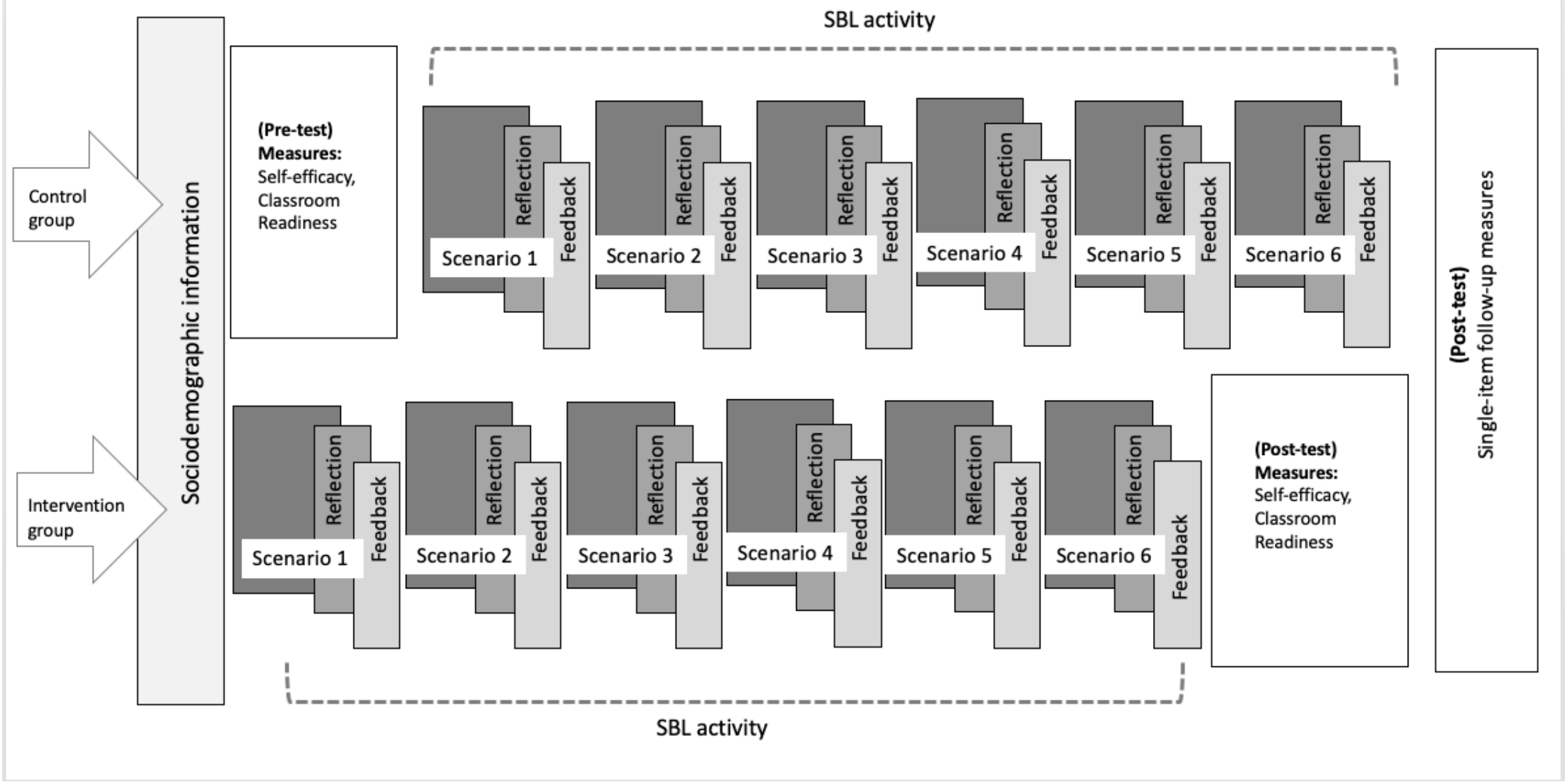

Figure 2. Research design of Study 2. 